Soad Al-Bahar

Ramesh Pandita

Bipin N. Savani

Ketan G. Bavishi

Department of Hematology,

Kuwait Cancer Control Center,

Kuwait

\section{Granulocyte Colony-Stimulating Factor Potentiated Severe Atypical Vincristine-Induced Neuropathy}

\section{Key Words}

Vincristine

Granulocyte colonystimulating factor

Neuropathy

\begin{abstract}
We report a patient with acute lymphoblastic leukemia who developed severe atypical neuropathy (SAN), distinct from classical vincristine neuropathy, following the use of vincristine and granulocyte colony-stimulating factor (G-CSF). SAN was characterized by acute onset of severe pain, exquisite tenderness on even light touch and profound motor weakness involving predominantly the lower limbs. The upper limbs were spared. Imaging studies and cerebrospinal fluid examination were normal. Electrophysiological studies showed axonal sensorimotor neuropathy. Potentiation of vincristine-induced neuropathy by G-CSF should be considered when formulating protocols using both these agents, and concomitant use of both the agents should be avoided.
\end{abstract}

\section{Introduction}

Vincristine and colony-stimulating factors (CSFs) are frequently used drugs in cancer patients. Both drugs have been incorporated in various protocols in hematologic malignancies, e.g. lymphoma and solid tumors such as small cell lung cancer. Neuropathy is a frequently recognized complication and the major limiting factor in the use of vincristine. Depression of Achilles tendon reflexes is the earliest sign of neurotoxicity and is noticed eventually in almost all patients receiving vincristine. Continuing therapy may induce paresthesias, motor weakness, and generalized depression of the deep tendon reflexes [1-3]. CSFs have been associated with numerous side effects but neuropathy has not been described [4]. Weintraub et al. [5] observed a severe atypical neuropathy (SAN) distinct from classical vincristine-induced neuropathy. SAN is characterized by acute onset of

\begin{tabular}{ll}
\hline KARGER & ( $1998 \mathrm{~S}$. Karger AG, Basel \\
1011-7571/98/0071-0068\$15.00/0 \\
$\begin{array}{l}\text { Fax +4161306 1234 } \\
\begin{array}{l}\text { E-Mail karger@karger.ch } \\
\text { www.karger.com }\end{array}\end{array}$ & $\begin{array}{l}\text { This article is also accessible online at: } \\
\text { http://BioMedNet.com/karger }\end{array}$
\end{tabular}

Dr. Soad Al-Bahar, MRCPath

Department of Hematology, Kuwait Cancer Control Center PO Box 12391

Al Shamya 71654 (Kuwait)

Tel. +9654812029 
excruciating foot pain, usually associated with marked motor weakness and, completely sparing the upper limbs. In their randomized study where chemotherapy was administered with and without CSFs, Weintraub et al. [5] strongly associated the use of CSFs with the risk of developing SAN. The lack of other reports on CSFs precipitating neurotoxicity is surprising, and could be due to the paucity of trials in which the use of CSFs is randomized and therefore the role of CSFs in neurotoxicity may not be apparent. We report a case of T-acute lymphoblastic leukemia (T-ALL), who developed severe atypical neuropathy following the administration of vincristine and granulocyte colony-stimulating factor $(\mathrm{G}-$ CSF).

\section{Case Report}

A 23-year-old man referred to the Kuwait Cancer Control Center on April 30, 1996, was diagnosed with T-ALL and acute renal failure. He was treated with parenteral antibiotics and hemodialysis. As his condition stabilized, he was initiated on intravenous (i.v.) vincristine, $2 \mathrm{mg}$ on days $1,8,15$, and 22 ; i.v. daunorubicin $45 \mathrm{mg} / \mathrm{m}^{2}$ on days 1 and 2; and oral prednisolone $45 \mathrm{mg} / \mathrm{m}^{2}$ on days $1-28$ from May 6,1996 . He received a total of 3 doses of vincristine (days 1, 8, and 15 of cycle 1) until May 20, 1996. Due to the lack of response an alternative protocol was initiated and he received i.v. vincristine $2 \mathrm{mg}$ (days 1,8 , and 15), oral cyclophosphamide $400 \mathrm{mg} / \mathrm{m}^{2}$ (days 1-4), i.v. doxorubicin $50 \mathrm{mg} / \mathrm{m}^{2}$ (day 1) with oral prednisolone $45 \mathrm{mg} /$ $\mathrm{m}^{2}$ from May 27, 1996. During the neutropenic period, he developed Klebsiella pneumoniae septicemia which was initially treated with ceftazidime, amikacin and later with imipenem. However his condition deteriorated rapidly. In view of resistant infection and prolonged neutropenia, G-CSF $300 \mu \mathrm{g} /$ day was administered from the 4th to the 11th of June 1996. He achieved complete remission which was confirmed by bone marrow examination.

On June 14, 1996, i.e., after 39 days of the first dose and 3 days after the last dose of vincristine, the patient developed sharp burning pain involving both the lower limbs, waist and back, and weakness on both lower limbs. Neurological examination showed that the pa- tient was alert and oriented with intact speech and intellectual function. The function of the cranial nerves was intact. Motor power was $5 / 5$ in the upper extremities without drift. The lower limbs were hypotonic with no fasciculations or abnormal movements; motor power was $0 / 5$ in both hip flexors, abductors and adductors, knee flexors, foot dorsiflexors, invertors and evertors. Deep tendon reflexes were normal for the upper limbs and absent for the knees and ankles. Superficial abdominal reflexes and plantar reflexes were absent bilaterally, and no Hoffman sign or jaw jerk was present. The sensory map is shown in figure 1. Sensations were also normal in the upper limbs. There was marked hyperesthesia below the level of T7 and the area of hypoesthesia above it up to T3/T4 on testing with pinprick and temperature sensation, involving both the anterior and posterior trunk. However, posterior trunk involvement was more ill-defined and the level was slightly lower than the anterior trunk involvement. Computerized tomography of the spine and brain and magnetic resonance imaging of the spine were normal. Lumbar puncture showed normal cerebrospinal fluid pressure and also clear fluid. Cerebrospinal fluid examination revealed normal sugar, protein and LDH; microscopic examination revealed no red, white or malignant cells. Cerebrospinal fluid culture was sterile after $48 \mathrm{~h}$. Nerve conduction studies showed a mixed sensory and motor axonal neuropathy. The details of nerve conduction studies are given in tables 1 and 2. After an initial rapid relief of pain, hyperesthesia and paresthesia, he was ambulatory but continued to have bilateral foot drop which was slowly improving. The patient received narcotics, steroids and physiotherapy. The temporal course of neuropathy and its relation to vincristine and G-CSF administration are given in figure 2. Neuropathy was graded according to Holland et al. [2]. After the plateauing of his neurological recovery, he was initiated on cranial irradiation and intrathecal methotrexate and showed no further change in his neurological status. His TALL is in complete remission.

\section{Discussion}

Vincristine-induced peripheral neuropathy is of mixed sensorimotor type affecting primarily the small fiber function [6]. The clinical spectrum of this complication is well documented and includes decreased deep tendon reflexes, distal paresthesias, sensory loss, 
Fig. 1. Sensory map.
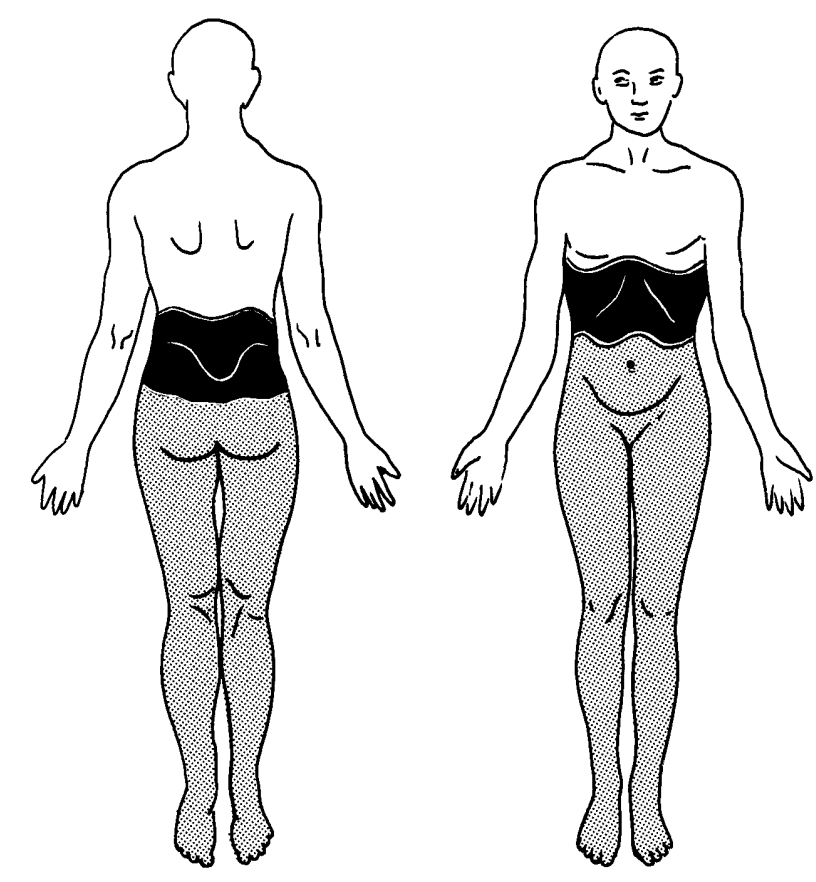

Hyperesthesia

Hypoesthesia

Table 1. Nerve conduction velocities: motor nerves

\begin{tabular}{lllll}
\hline Motor nerve & $\begin{array}{l}\text { Motor } \\
\text { conduction } \\
\text { velocities } \\
\mathrm{m} / \mathrm{s}\end{array}$ & $\begin{array}{l}\text { Terminal } \\
\text { motor } \\
\text { latency } \\
\mathrm{ms}\end{array}$ & $\begin{array}{l}\mathrm{F}(-) \mathrm{M} \text {-wave } \\
\text { latency } \\
\mathrm{ms}\end{array}$ & $\begin{array}{l}\text { M-wave } \\
\text { amplitude } \\
\mathrm{mV}\end{array}$ \\
\hline $\begin{array}{l}\text { Rt. median } \\
\text { Rt. ulnar }\end{array}$ & 57 & 2.6 & 20 & $1.3 / 1.3$ \\
$\begin{array}{l}\text { Rt. peroneal } \\
\text { Rt. tibial }\end{array}$ & 57 & 2.8 & 22 & $5.8 / 4.6$ \\
& 29 & 11.1 & $\mathrm{NR}$ & $0.05 / 0.04$ \\
& 34 & 6.9 & 57 & $0.7 / 0.5$ \\
\hline
\end{tabular}

NR = Not recorded . 


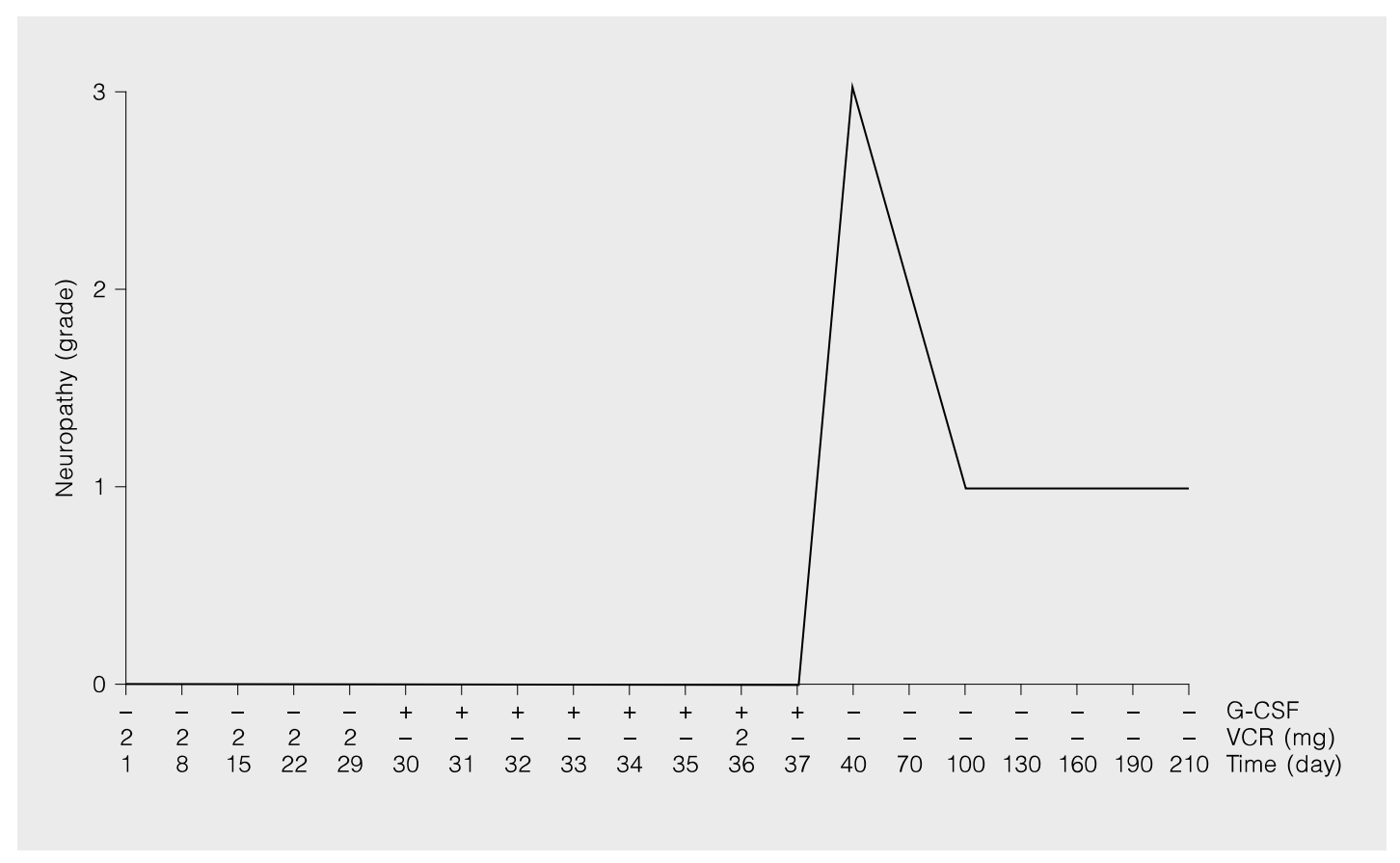

Fig. 2. Temporal relation between vincristine (VCR), G-CSF and neuropathy.

Table 2. Nerve conduction velocities: sensory nerves

\begin{tabular}{|c|c|c|}
\hline Sensory nerve & $\begin{array}{l}\text { Sensory } \\
\text { conduction } \\
\text { velocities } \\
\mathrm{m} / \mathrm{s}\end{array}$ & $\begin{array}{l}\text { Amplitude } \\
\text { nerve action } \\
\text { potential } \\
\text { uV }\end{array}$ \\
\hline Rt. median to index & 62 & 10 \\
\hline Rt. ulnar to 5th finger & 58 & 8.5 \\
\hline Rt. sural & no response & no response \\
\hline
\end{tabular}

motor weakness, muscle wasting and muscle pain [2]. Neuropathy due to CSF has not been described [4]. Weintraub et al. [5] recently described SAN due to vincristine and CSFs. SAN was characterized by constant severe, sharp or burning pain confined to the feet, which develops acutely with minimal or no prodrome. The pain occurred in stocking distribution, prominently in the toes and soles of the feet in mild cases. The pain was severe and the patient was unable to tolerate even light touch, and unable to stand and walk. The upper limbs were completely spared. Nine of the 12 patients reported by Weintraub et al. [5] had severe motor neuropathy, manifested by complete foot drop and muscle power grade 0 to 2/5. The clinical course of SAN can be variable and some show quick recovery in a few days, while in others the recovery may be slow and may take several months. However, most of the patients recovered completely. In their randomized study where chemotherapy was administered with and without CSF, Weintraub et al. observed a highly significant association between SAN and the ad- 
ministration of CSFs. Of the 26 patients who did not receive CSFs, 1 (4\%) developed SAN, and of the 28 patients who received CSFs, 11 (39\%) developed SAN [5]. Our patient had a more severe form of toxicity than the case reported by Weintraub et al. [5]. Our patient had an extensive distribution of severe pain which involved the lower limbs, waist and back, excluding the upper limb, and required narcotics. The patient was unable to sit or walk. The level of truncal involvement was higher on the anterior trunk. Similar truncal involvement by polyneuropathy has been described in patients with diabetes mellitus [7]. The sensory neuropathy rapidly recovered but the motor recovery was slow. Although the patient's muscle power has improved and he is ambulatory, a minimal foot drop still persists and is slowly recovering. The CSFpotentiated vincristine SAN is dose-related with higher cumulative doses associated with higher risk of SAN [5]. Our patient received a cumulative dose of $12 \mathrm{mg}$ of vincristine. Greater toxicity in our patient could be related to either a higher cumulative dose of vincristine followed by G-CSF administration or to concomitant administration of G-CSF and vincristine. In our patient SAN developed 39 days after the first and 3 days after the last dose of vincristine. Similar temporal relation has been documented by Weintraub et al. [5]. Patel et al. [8] have reported severe neurotoxicity in 4 patients who received ifosfamide and G-CSF, and hypothesized that ifosfamide exacerbated a preexisting neuropathy, and it is possible that G-CSF may have exacerbated ifosfamide neurotoxicity in these patients. Our patient received cyclophosphamide and doxorubicin, but both these drugs have not been reported to cause peripheral neuropathy when used alone or in combination with other agents [9]. Although the relationship between cytokines, CSFs, nerve growth and differentiation factors is well recognized [10], the mech- anism of action of CSFs in causing neurotoxicity is not clear. It is possible that CSFs directly or indirectly interfere with nerve growth or viability factors involved in the damaged nerves [5]. CSFs stimulate the production of tumor necrosis factor alpha and interleukin-1 [11], and high levels of interleukin-1 are toxic to neural tissue [12]. It is also possible that this neurotoxic effect may be even more pronounced in nerve fibers which were previously damaged by agents like vincristine. The exclusive involvement of the lower limbs by SAN and the difference from classical vincristine neuropathy suggest that it may affect, at least in part, different subsets of nerve fibers [5].

In conclusion, G-CSF used in conjunction with vincristine may potentiate vincristineinduced neuropathy, and caution is required in their concomitant use. Further studies are required for a better understanding of CSF-potentiated neurotoxicity and their prevention and treatment. 


\section{References}

1 Sandler SG, Tobin W, Henderson ES: Vincristine induced neuropathy: A clinical study of fifty leukemic patients. Neurology 1969;19:367-374.

2 Holland JF, Scharlau C, Gailani S: Vincristine treatment of advanced cancer: A cooperative study of 392 cases. Cancer Res 1973;33:12581264.

3 Casey EB, Jellife AM, Quesne PM, Millet YL: Vincristine neuropathy: Clinical and electrophysiological observations. Brain 1973;96:69-86.

4 Schriber JR, Negrin RS: Use and toxicity of the colony stimulating factors. Drug Safety 1993;8:457468.
5 Weintraub M, Adde MA, Venzon DJ, Shad AT, Horak ID, Neely JE, Seibel NL, Gootenberg J, Arndt C, Nieder ML, Magrath IT: Severe atypical neuropathy associated with administration of hematopoietic colony-stimulating factors and vincristine. J Clin Oncol 1996;14:935940.

6 Kaplan RS, Wiernik PH: Neurotoxicity of antineoplastic drugs. Semin Oncol 1982;9:103-130.

7 Waxman SG, Sabin TD: Diabetic truncal polyneuropathy. Arch Neurol 1981;38:46-47.

8 Patel SR, Forman AD, Benjamin RS: High dose ifosfamide-induced exacerbation of peripheral neuropathy. J Natl Cancer Inst 1994;86: 305-306.
9 Aisner J, Weirnik PH, Esterhay RJ Jr: Treatment of small cell carcinoma of the lung with cyclophosphamide, adriamycin and VP-16-213 with or without MER. Adj Ther Cancer 1977;QZ 267146 a:245250.

10 Bazan JF: Neuropoietic cytokines in the hematopoietic fold. Neuron 1991;7:197-208.

11 Sisson SD, Dinarello CA: Production of interleukin-1alpha, interleukin-1beta and tumor necrosis factor by human mononuclear cells stimulated with granulocyte-macrophagecolony stimulating factor. Blood 1988;72:1368-1374.

12 Merrill JE: Tumor necrosis factor alpha, interleukin-1 and related cytokines in brain development: Normal and pathological. Dev Neurosci 1992;14:1-10. 